\title{
Serebral palsi tedavisinde ortezlemede yenilikler
}

\author{
Innovations in orthosis in the management of cerebral palsy
}

\author{
Demet Ofluoğlu
}

Bahçeşehir Üniversitesi Tıp Fakültesi, Fiziksel Tıp ve Rehabilitasyon Ana Bilim Dalı, İstanbul

\begin{abstract}
Serebral palsi (SP)'de, ortez kullanımı hem cerrahi öncesinde hem de sonrasında, meydana gelen kas-iskelet sistemi deformitelerinin önlenmesinde ve yürüme gibi işlevselliğin artırılması amacıyla kullanılır. En sık kullanılan cihazlar ayak - ayak bileği ortezleri (AFO, Ankle Foot Orthosis)'dir. Farklı AFO tipleri farklı deformiteler için kullanılmaktadır. Klasik cihazların yanı sıra son zamanlarda yürümeye yardımcı robotik sistemler üzerinde çalışmalar devam etmektedir. Bu cihazlar gelecekte klasik ortezlerin yerini alabilir mi? Bu derlemede SP'de yürüme desteği için kullanılan eski ve yeni teknolojik cihazlardan bahsedilecektir.
\end{abstract}

Anahtar sözcükler: serebral palsi; ortezleme; cihazlama; yenilikler; ayak - ayak bileği ortezleri
In Cerebral Palsy (CP), orthotic devices are used to prevent musculoskeletal deformities, and in the assistance of functionalities such as walking in both pre- and post-operation phase. The most commonly used equipment is Ankle-FootOrthosis (AFO). Different types of AFOs are used for different types of deformities. Studies on robotic systems used alongside classical equipment that assist in walking will continue to take place. Can these new devices replace classical orthosis devices? In this review, we will discuss new and old technologies and devices used for assistance during walking in $\mathrm{CP}$ patients.

Key words: cerebral palsy; orthosis; device; innovations; ankle-foot-orthosis erebral palsi (SP)'de, ortez kullanımı hem cerrahi öncesinde hem de sonrasında, meydana gelen kas-iskelet sistemi deformitelerinin önlenmesinde, işlevi artırmada önemli bir yere sahiptir. Serebral palside en sık reçete edilen ortezler alt ekstremite ortezleri olup, bu grup içinde de en sık kullanılanlar ayak - ayak bileği ortezleri yani kısaca AFO (Ankle-Foot Orthosis)'lardır. Nörolojik bozukluk, proksimalden çok distal bölgeleri etkiler. SP'de zayıflık ve motor kontrol eksikliği diz ve kalçadan ziyade ayaklarda daha fazladır. Bu ayak bozuklukları giderek diz ve kalçada ek dizilim bozuklukları meydana getirir. Bu nedenle AFO'ların kullanımı tercih edilir.

Pratik olarak yürüyebilen bir SP'li çocukta işlevsel sorunları düzeltmek için kalça - diz - ayak - ayak bileği (HKAFO, Hip Knee Ankle Foot Orthosis) tarzı ortezler kullanılmaz. Bu tip ortezler ancak ambulasyonu olmayan (yürüyemeyen) veya kalça cerrahisi geçiren uygun hastalara verilir. Benzer olarak diz-ayak-ayak bileği ortezleri (KAFO, Knee Ankle Foot Orthosis) de diz eklemi dizilimini sağlamak için özellikle botulinum toksin veya çok seviyeli cerrahiler sonrası kullanılmaktadır. İşlevsel sebeplerle yürümeye yardımcı olması için SP'de KAFO'lar pek tercih edilen cihazlar değildir.

Serebral palside klasik olarak en sık kullanılan ortezler AFO'lardır. Ortez reçetelemedeki temel hedef yürüyebilen (ambulatuvar) ve yürüyemeyen (nonambulatuvar) çocuklarda farklılıklar gösterir (Tablo 1). Yürüyemeyen çocukta AFO kullanımı ile temel hedef, ayak deformitelerini düzeltmek, kontraktürü önlemek iken, hareketli, yürüyebilen (ambulatuvar) çocuklarda ise deformiteyi düzeltmenin ve önlemenin yanı sıra yürümeye (ambulasyona) yardımcı olmak ve yürüme sırasında ayak mekaniğini düzeltmektir. Bu amaçla bağımsız yürüme yeteneği olmayan çocuklarda en çok tercih edilen alt ektremite ortezi solid (eklemsiz) AFO'dur. Yürüme dönemi öncesinde (Pre-ambulatuvar) çocuklarda solid (eklemsiz) AFO kullanımının yürümeyi hızla geliştirdiği ve bağımsız yürümeye yardımcı olduğu gösterilmiştir. ${ }^{[1]}$ Çocuğun gelişimi sırasında ise değişen

- İletişim adresi: Prof. Dr. Demet Ofluoğlu, Bahçeşehir Üniversitesi Tıp Fakültesi, Fiziksel Tıp ve Rehabilitasyon Ana Bilim Dalı, İstanbul

Tel: 0533 - 6009542 e-mail: dofluoglu@hotmail.com

- Geliștarihi: 28 Șubat $2021 \quad$ Kabul tarihi: 22 Mart 2021

ORCID iD: Demet Ofluoğlu, 0000-0003-4273-5518 
Tablo 1. SP'de ambulasyona göre ortez kullanım hedefleri

\begin{tabular}{ll}
\hline Non-ambulatuvar (Yürüyemeyen) & Ambulatuvar (Yürüyebilen) \\
\hline$>$ Ayak pozisyonunu düzeltmek & $>$ Deformite ve kontraktürü önlemek \\
$>$ Deformite ve kontraktürü önlemek & $>$ Yürüme bozukluklarını düzeltmek \\
$>$ Terapötik (Tedavi) amaçlı ayakta durmaya yardımcı olmak & $>$ Basma fazında stabilite sağlamak \\
& $>$ Salınım fazında ayağın yerden kesilmesini sağlamak \\
& $>$ ilk temas için ayağı uygun pozisyonda tutmak \\
& $>$ Yeterli adım uzunluğu sağlamak \\
& $>$ Enerjiyi korumak
\end{tabular}

deformite ve kas gücüne bağlı olarak cihazlar değiştirilebilir. Yürüme yeteneği olan SP'li çocuklarda ise cihaz seçimi mevcut deformite ve spastisite, spastisite şiddetine göre farklılıklar gösterir. Aynı zamanda, eklemler üzerine etkisinden ayrı olarak, yürüyebilen çocuklarda yer tepkime kuvvetleri üzerine olan etkilerinden dolayı yürüme mekaniğini etkilemek AFO'lar ile mümkündür. ${ }^{[2,3]}$ Ayrıca AFO'ların tipleri, kullanılan materyalleri ve sertlikleri yürüme üzerine farklı etkiler gösterir. Aşağıda farklı AFO çeşitleri, özellikleri ve hangi durumlarda kullanılacağı tartışılacaktır.

\section{SEREBRAL PALSIDE SIK KULLANILAN ORTEZLER VE ÖZELLIKLERI}

\section{Eklemsiz (Solid) AFO}

Proksimalde fibula başının hemen distaline kadar uzanan, distalde metatars başlarında veya parmak uçlarında sonlanan, yan kenarları varus/valgus kontrolünü sağlayacak yükseklikte olan, sert, bükülmeyen malzemeden yapılmış, eklemsiz ortezlerdir (Şekil 1a). Solid AFO'nun başlıca kullanım endikasyonları yürüyemeyen çocuklarda spastisiteyi azaltmak, deformite ve kontraktürü önlemek, ameliyat sonrası dönemde stabiliteyi sağlamak; yürüyebilen çocuklarda ise ağır spastisiteyi azaltmak, basma fazı sırasında stabiliteyi sağlamak ve salınım fazı sırasında da ayağın yerden temasının kesilmesine yardımcı olmaktır. ${ }^{[4,5]}$ SP'de hem tek taraflı hem de iki taraflı tutulumlarda kullanılabilir.

\section{Eklemli AFO}

Eklemsiz AFO'dan farklı olarak, anatomik ayak bileği eklemi eksenine uygun pozisyonda hareketli parça (eklem) içeren AFO'lardır (Şekil 1b). Genellikle yürüyebilen, aktif, merdiven ve yokuş inip çıkabilen çocuklarda kullanılır. Bu çocuklarda eklemli AFO basma stabilitesini artırır, ilk temasın normalleştirilmesini sağlar, diz instabilitesini kontrol eder ve salınım fazında ayağın yerden kesilmesini sağlar. Eklemli AFO kullanmanın ön şartı, pasif ayak bileği dorsifleksiyonunun en az $5^{\circ}$ olmasıdır. ${ }^{[6]}$ Eklemli AFO'lar ayak bileği plantar fleksiyonunu önler, dorsifleksiyona izin verir ve böylece basma fazı sırasında ayak üzerindeki ikinci dönmeyi (rocker) kolaylaştırır ve ikinci dönmeden üçüncü dönmeye geçerken enerji emilimini sağlayarak parmak kalkışını (push-off) artırır. Ek olarak, patolojik ayak bileği plantar fleksiyonu-diz ekstansiyonu çiftini normalleştirir. Buna bağlı olarak diz ve kalça eklem biyomekaniği üzerine de etki sağlar. Örneğin ayak bileği dorsifleksiyon açısının artırılması ile dizde fleksiyon momenti yaratılarak genu rekurvatum deformitesini kontrol eder. Solid (Eklemsiz) AFO'ların bir dezavantajı olan parmak kalkışının bozulması, eklemli AFO'ların kullanımı ile minimalize edilir. ${ }^{[7]}$ Eklemli AFO'lar yürüme sırasında eklemlerdeki açısal değerleri düzeltmenin yanı sıra (ilk teması parmak ucu olan SP'li bir çocukta, ilk teması topuk vuruşuna çevirmek gibi), kas aktiviteleri üzerine etki eder. ${ }^{[8]}$ Aynı zamanda enerji korumalı bir yürüme sağlar. ${ }^{[9]}$

\section{Yer Tepkimesi AFO (YTAFO)}

Solid AFO'ya benzerdir. Farkı, proksimalde ön yüzden kapalı olmasıdır. Böylece, basma fazı sırasında tibianın ayak üzerinde öne translasyonunu (yer değiştirmesini) engeller ve dizde ekstansiyon momenti yaratır (Şekil 1c). ${ }^{[10]}$ Kuadriseps kasının gerektirdiği enerjiyi azaltır. Bükük diz yürüyüşü (basma fazı sırasında artmış diz fleksiyonu ve ayak bileği dorsifleksiyonu) yapan SP'li çocuklarda kullanılır. Dizde ve kalçada $15^{\circ}$ 'den fazla fleksiyon kontraktürü, $15^{\circ}$ 'den fazla eksternal rotasyonu ve ekino-planovalgus deformitesi olan olgularda kullanılmaz. Bu cihazın iyi tolere edilebilmesi için, diz ekstansiyonda iken ayak bileği en azından nötral posizyona gelecek şekilde dorsifleksiyon yapabilmelidir. ${ }^{[11]} \mathrm{Diz}$ üzerine etkilerinin yanı sıra ayak ekleminde plantar fleksiyonu kısıtlayarak ekin deformitesinin kontrolüne de yardımcı olur. ${ }^{[12]}$ Uygun hasta seçimi ile bükük diz yürüyüşünde YTAFO kullanımı ile $10-28^{\circ}$ 'lik bir ekstansiyon kazanımı elde edilebilir. ${ }^{[13]}$ 

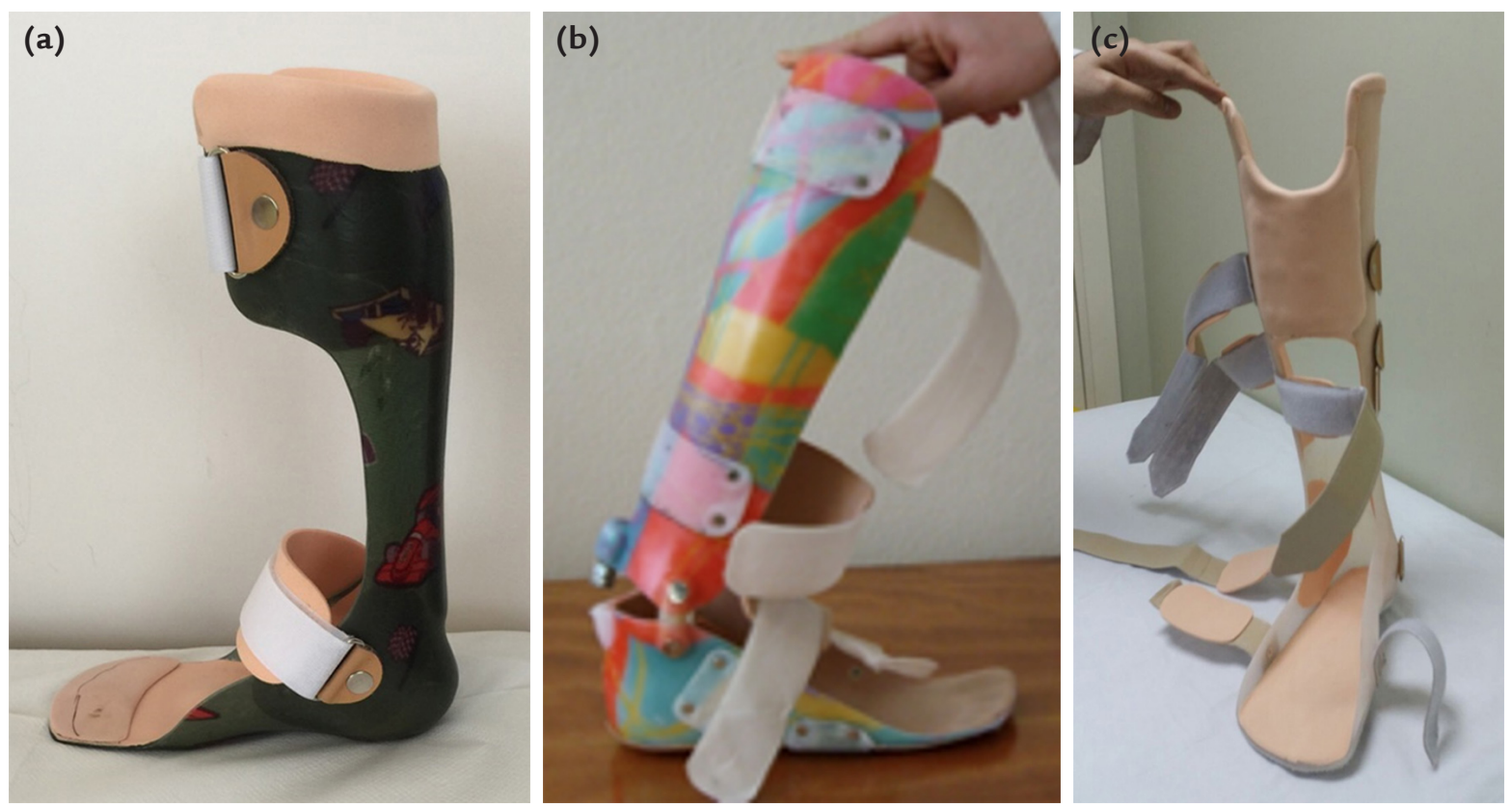

Şekil 1. a-c. Solid (Eklemsiz) AFO (a); eklemli AFO (b); Yer Tepkimesi AFO (YTAFO) (c).

Gerek eklemsiz AFO'lar gerekse YTAFO'lar gibi eklemsizAFO'lar ayak bileği hareketlerini etkin bir biçimde kısıtlar. Bu nedenle kullanımları özellikle yürüyebilen çocuklarda sıkıntı yaratabilir. Bu YTAFO'ların plantar fleksiyona izin veren, fakat dorsifleksiyonu kısıtlayan eklemli modelleri bulunmaktadır. Bunlar, genellikle cerrahi uzatmalardan sonra plantar fleksör kas gücünü artırmak amacıyla ve hastayı daha sonra ortezsiz yürümeye hazırlamak amacıyla kullanılır. ${ }^{[11]}$

\section{Refleks AFO (Posterior Leaf Spring Ortezleri - PLSO)}

Solid (Eklemsiz) ortezin yan kenarlarının malleollerin posteriorunda bitirilmesi ile elde edilen PLSO, görünürde eklemsiz olan; fakat, mekaniği nedeniyle basma fazında pasif dorsifleksiyona izin veren bir ortezdir (Şekil 2a). Salınım fazında ise düşük ayağı önler. Hafif spastik ve dinamik ekin deformitesi olan çocuklarda kullanılabilir. Orta-ağır derecede spastisite, sabit ekin deformitesi ve medio-lateral instabilite varlığında kullanılması yararlı değildir. Geleneksel PLSO spastisite üzerine etkili olmadığından, medio-lateral instabilite de eşlik edebileceğinden kısmen PLSO'nun avantajlarından ve kısmen de solid (eklemsiz) AFO etkilerinden yararlanabilmek için PLSO'nun ayak stabilitesi artırılabilir ve sertliği artırmak için posterior güçlendirme konularak modifiye edilebilir. Bu tip orteze modifiye PLSO denilebilir. (Şekil $2 b$ ve $2 c) .{ }^{[6]}$

\section{Dinamik AFO (DAFO)'lar, Supra ve Inframalleoler Ortezler}

DAFO'lar hipertonik ayak refleks aktivitesini azaltmak amacıyla kullanılan supramalleoler ortezlerdir. Bunlar oldukça ince ve esnek olup, tam temas sağlayarak, ayağın dinamik arkını destekler ve stabilize eder. Her üç planda az miktarda harekete izin verir. Subtalar eklemlerin medio-lateral instabilitesinde, ayak önünde varus/valgus deformitesine neden olan ayak ortası instabilitelerinde, hafif-orta spastisite varlığında ve hipertonik ayak refleks aktivitesini azaltmak amacıyla kullanılır. ${ }^{[14]}$ Refleks yolla tonusu azaltmaları ek yarar sağlamaktadır. ${ }^{[15]}$ Supramalleoler ve UCBL (University of California Biomechanics Laboratory) gibi inframalleoler tarzı ayak ortezleri deformite gelişimi üzerine bazı etkileri olsa da yürüme üzerine etkileri yok denecek kadar azdır. İnframalleoler ortezler sagittal plan ayak hareketleri üzerine etkili değildir. Supramalleoler ortezlerin ise sagittal planda ayak hareketlerine etkisi sınırlıdır.

\section{AFO KULLANIMININ YÜRÜME VE FONKSIYONELLIK ÜZERINE ETKILERI}

Spastik diplejik çocuklarda solid (eklemsiz) AFO, eklemli AFO ve refleks AFO'nun proksimal eklem dinamikleri, enerji harcaması ve işlevsel beceri performansı üzerine etkilerini araştıran bir çalışmada, tüm AFO tiplerinin basma fazında ayak bileği hareketlerini normalleştirdiği görülmüştür. Bunun yanı sıra, adım 

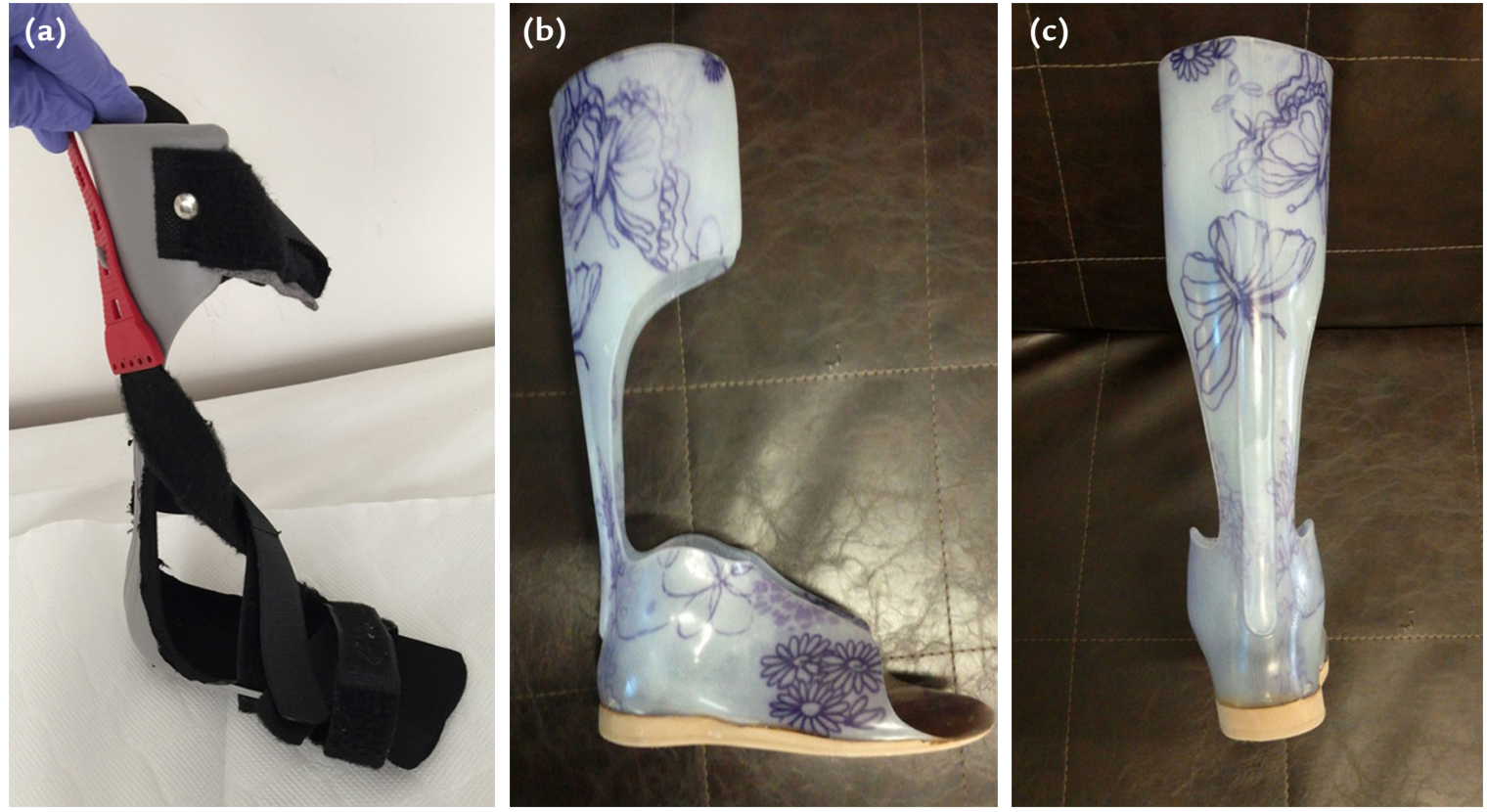

Şekil 2. a-c. PLSO (a) ve modifiye PLSO (b) lateral görünüm; modifiye PLSO posterior görünüm (c).

uzunluğunun arttı̆̆ı, kadansın (birim zamanda atılan adım sayısının) azaldığı ve yürüme sırasında enerji tüketiminin azaldığı; ek olarak, yürüme, koşma, zıplama ve üst ekstremite becerilerinde iyileşme olduğu gözlenmiştir. Motor becerilerdeki kalite ve bağımsız yürüme üzerine AFO kullanımlarının bir etkinliği gözlenmemiştir. ${ }^{[16]}$ Hemiparetik SP'li çocuklarda ise aynı araştırmacıların yaptığı her üç tip AFO'nun yürüme üzerine değerlendirmesinde hem eklemli $A F O$ ile hem de PLSO ile yürümedeki düzelme ve enerji harcanmasındaki azalmanın daha belirgin olduğu gösterilmiştir. ${ }^{[17]}$ Wren ve ark.'nın yaptığı bir çalışmada bükük diz ve ekin yürüyüşü yapan SP'li çocuklarda modifiye PLSO ve eklemli AFO karşılaştırılmıştır. Yürüme analizi verileri her iki tip AFO'nun kullanılması ile düzelmiştir. Eklemli AFO kullanımı ile salınım öncesi itme gücünün daha iyi olduğu, daha enerji korumalı bir yürüme biçiminin olduğu gözlenmiştir. Modifiye PLSO benzeri, yazarların dinamik AFO dedikleri ortez kullanımında ise daha kozmetik olması ve daha kolay giyilebilmesi nedeniyle hasta memnuniyeti daha iyi olmuştur. ${ }^{[18]}$

Radtka ve ark., spastik SP'li (altı diplejik, dört hemiplejik) 10 hastada birer aylık dönemlerle DAFO, Solid (eklemsiz) AFO ve AFO'suz karşılaştırmalar yapmışlar ve her iki tip ortezin de adım uzunluğunu, kadansı (birim zamandaki adım sayısını) artırdığı, aşırı plantar fleksiyonu azalttığını tespit etmişlerdir.
[19] Diğer taraftan Romkes ve Brunner spastik ekin deformitesi olan SP'li çocuklarda DAFO'nun etkinliğini eklemli AFO ile karşılaştırmışlardır. Bu çalışmada DAFO'nun, eklemli AFO ile olanın aksine, spastik ekin deformitesini önlemediğini göstermişlerdir. ${ }^{[20]} \mathrm{Her}$ ne kadar refleks olarak spastisiteyi azalttığı düşünülse de, DAFO'lar kaldıraç kolunun kısa olması nedeniyle ağır spastisitesi olan olgularda ekin deformitesini önlemede yetersiz kalır. Bu nedenle supramalleoler ortezler gibi düşünülerek bu endikasyonlar çerçevesinde kullanılmalıdır.

SP'de farklı yürüme bozukluklarına göre uygun ortez tipleri Tablo 2'de gösterilmiştir. ${ }^{[6]}$ Burada bir ortezin farklı yürüme bozukluklarında kullanılabileceği veya bir yürüme bozukluğunda farklı ortezlerle kontrolün mümkün olabileceği görülmektedir. Örneğin, bükük diz yürüyüşü hem eklemsiz AFO hem de YTAFO'su ile eşit derecede kontrol edilebilir. ${ }^{[21]} \mathrm{Bu}$ durumda çocuğun hangi ortezi kullanabileceği, endikasyonlar-kontrendikasyonlar çerçevesinde değerlendirilerek seçim yapılabilir. Bir ortez reçetelemeden önce mutlaka iyi bir fizik muayene yapılmalı, deformitenin nerede olduğu, ne tip bir yürüme bozukluğunun olduğu analiz edilmeli, ortez kullanım amaçları iyi belirlenmeli, çocuğun ve ailenin beklentileri, gereksinimleri göz önünde bulundurulmalıdır. Yapılan çalışmalarda AFO kullanmanın, pasif-aktif ayak bilek hareketi, yürüme kinetik ve kinematiği, mobilite ile 
Tablo 2. SP'de yürüme tiplerine göre tavsiye edilen ortezler ${ }^{[6]}$

\begin{tabular}{|c|c|c|c|}
\hline Yürüme biçimi & Ortez seçenekleri & Hedef & Anahtar noktalar \\
\hline Ekin deformitesi & $\begin{array}{l}\text { Solid (Eklemsiz) AFO } \\
\text { Modifiye PLSO } \\
\text { Eklemli AFO }\end{array}$ & $\begin{array}{l}>\text { Basma fazında stabilite ve salınım } \\
\text { fazında klirens (kurtulma) sağlamak } \\
>\text { Mümkünse DF'ye izin vermek }\end{array}$ & $\begin{array}{l}\text { Ayak bileğinin DF’sini göz önünde bulundurmak } \\
\text { AFO içinde ayak ortasının stabilitesinin } \\
\text { sağlanması }\end{array}$ \\
\hline Sıçrama yürüyüşü & $\begin{array}{l}\text { Solid (Eklemsiz) AFO } \\
\text { Modifiye PLSO }\end{array}$ & $\begin{aligned} & \text { Basma fazında stabilite ve salınım } \\
& \text { fazında klirens (kurtulma) sağlamak } \\
&> \text { Mevcut PF kontraktürüne uyum } \\
& \text { > Ayak ortasının bükülmesini önlemek } \\
&>\text { PF-DE çiftini normalleştirmek }\end{aligned}$ & $\begin{array}{l}\text { Ayak bileğinin DF’sini göz önünde bulundurmak } \\
\text { AFO içinde ayak ortasının stabilitesinin } \\
\text { sağlanması } \\
\text { Diz ekstansiyonunun artırılabilmesi için yeterli } \\
\text { sertliğin sağlanması }\end{array}$ \\
\hline Görünür ekin & $\begin{array}{l}\text { SAFO } \\
\text { YTAFO }\end{array}$ & $\begin{aligned} & \text { Basma fazında stabilite ve salınım } \\
& \text { fazında klirens (kurtulma) sağlamak } \\
& \text { ilk temasta topuk vuruşu } \\
& \text { İstenmeyen veya artmış tibial öne gidişi } \\
& \text { önlemek } \\
> & \text { PF-DE çifti işlevini sağlamak }\end{aligned}$ & $\begin{array}{l}\text { Spastisitenin derecesi } \\
\text { Ayakkabı içinde AFO'nun uygun pozisyonu } \\
\text { Tamamlayıcı yaklaşımlar } \\
\text { Diz ekstansiyonunun artırılabilmesi için yeterli } \\
\text { sertliğin sağlanması }\end{array}$ \\
\hline Bükük diz yürüyüşü & YTAFO & $\begin{array}{l}\text { PF-DE yeniden sağlanması sırasında } \\
\text { kuadriseps ihtiyacını azalmak } \\
>\text { Kaldıraç kolu disfonksiyonunu önlemek }\end{array}$ & $\begin{aligned} & \text { Ayak bileğinin DF’sini göz önünde bulundurmak } \\
& \text { Transvers plan kemik deformiteleri için ortopedik } \\
& \text { cerrahilerin düşünülmesi } \\
& \text { > AFO içinde ayak ortasının desteklenmesi } \\
& \text { > Ayakkabı içinde AFO'nun uygun pozisyonu } \\
& \text { D Diz ekstansiyonunu artırmak için yeterli sertliğin } \\
& \text { sağlanması } \\
& \text { > Tamamlayıcı yaklașımlar }\end{aligned}$ \\
\hline
\end{tabular}

DF, dorsifleksiyon; PF, plantar fleksiyon; PF-DE, Plantar fleksiyon - diz ekstansiyon çifti; SAFO, Solid (Eklemsiz) AFO; YTAFO, Yer tepkime AFO'su.

ilişkili işlevsel aktiviteler üzerine olumlu etkileri gösterilmiştir. ${ }^{[21]}$ Ayrıca, AFO kullanımının kaba motor işlevleri üzerine etkinliğini araştıran çalışmalarda, AFO'nun kaba motor işlevlerin düzelmesine orta dereceli etki sağladığı gösterilmiştir. ${ }^{[22]}$ Fakat çalışmaların kalitesi kanıta dayalı tıp kapsamında düşüktür. Bu nedenle daha kaliteli çalışmalara gereksinim vardır.

\section{ORTEZLEMEDE YENILIKLER: ROBOTIK ORTEZLER}

Günümüzde teknolojinin ilerlemesi ile nöro-rehabilitasyon alanında gerek hareketliliğin artırılması gerekse günlük yaşam aktivitelerinin ve iletişim gibi becerilerin iyileştirilmesi için tedavi yaklaşımlarında farklılıklar olmuştur. Nöro-rehabilitasyon alanında teknolojilerin kullanılması nöroplastisite teorisine dayanmaktadır. Motor öğrenme prensipleri ve nöroplastisite hareketin kalitesinin artırılması amacıyla kullanılır. Nöroplastisite işlevi artırmak için yüksek yoğunluklu tekrarlayan hareketlerin yapılması sonucu gelişir. Robotik teknolojiler nöroplastisiteyi geliştirecek tekrarlayan hareket biçimlerinin uygulanmasına destek olur. Aynı zamanda eklemleri destekler, hareketlere yardımcı olur ve gerçek zamanlı geri bildirim sağlar.
Mobiliteye yardımcı olan robotik cihazları; 1) yürüme eğitimi yapanlar, 2) alt ve üst ekstremite robotları ve 3 ) giyilebilen robotik cihazlar (ekzo-iskelet) olarak sınıflandırabiliriz.

Yürüme eğitimi yapanlar sabit, kliniklerde kullanılan robotik cihazlardır (Şekil 3). Özellikle kaba motor işlev sınıflamasında evre 1 ve 2 olan çocuklarda yürüme hızını, motor işlevi ve endüransı (dayanıklılığı) artırdığı bilinmektedir. ${ }^{[23]}$ Fakat bu sistemler her ne kadar işlevselliğe katkıları olsa da sadece klinik ortamlarında eğitim amaçlı kullanılabilir.

Alt ve üst ekstremite robotik sistemler hem klinik kullanım hem de ev kullanım amaçı üretilir. Bu robotik sistemlerin kullanılması ile eklemlerde hareket açıklıkları artırılabilir, spastisite ve kas kısalıkları azaltılabilir, egzersizler oyun bazlı ve hedefe yönelik bir şekilde yaptırılır. Böylece işlevsel anlamda kazanımlar elde edilir. Fakat yürüme eğitimi yapan sabit robotik cihazlar gibi bunlar da temelde alt ekstremite için yürüme eğitiminde, üst ekstremite içinde el rehabilitasyonunda kullanılır. Dolayısıyla aktiviteler sırasında ortezler gibi destekleyici özellikte değildirler. ${ }^{[24,25]}$

Giyilebilen robotik cihazlar, bir motor yardımı ile günlük aktiviteler sırasında hareketin yapılmasına destek olur. Daha çok yürüme amaçlı üretilmişlerdir. Bu 


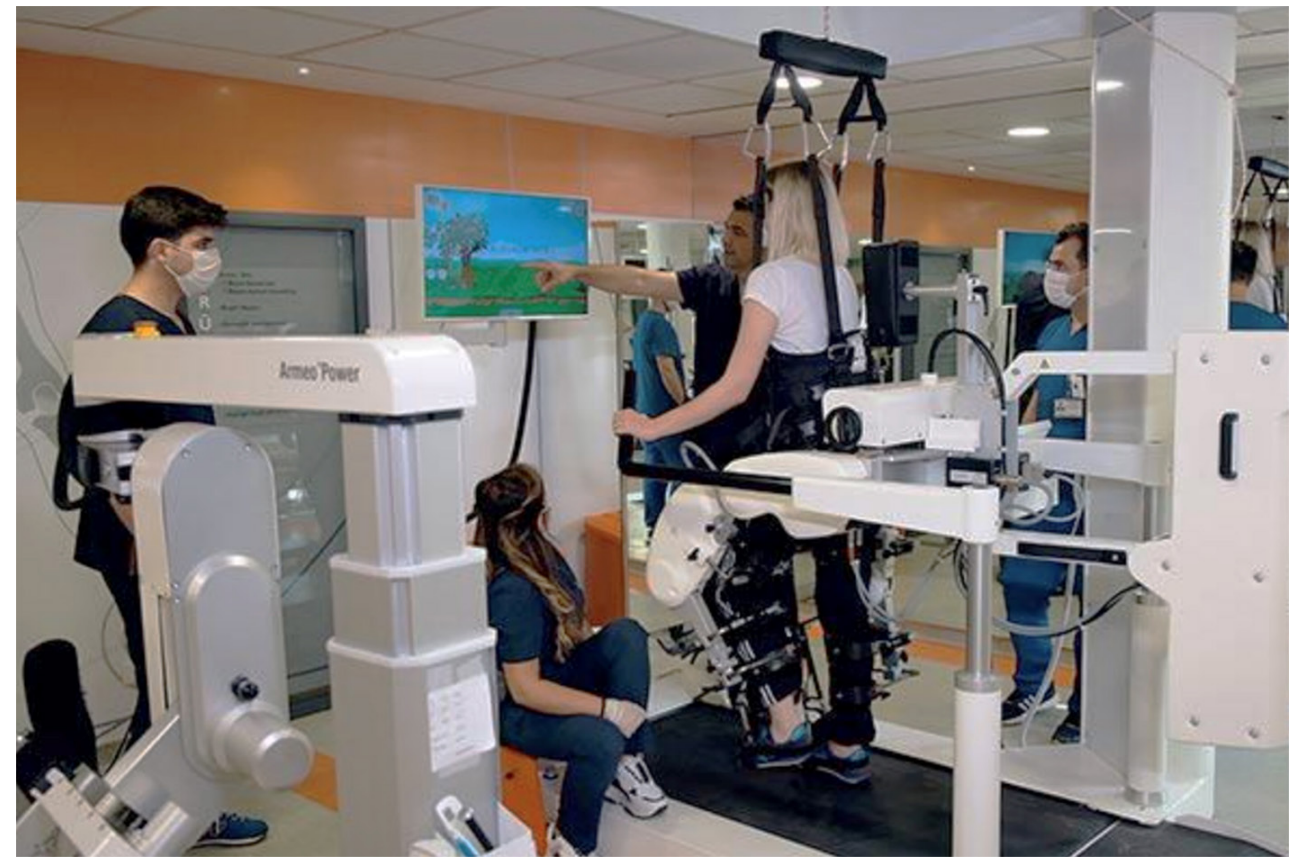

Şekil 3. Yürüme eğitimi yapan, kliniklerde kullanılabilen sabit yürüme robotları.

nedenle ekzo-iskelet olarak da isimlendirilir. Mikrobasınç algılayıcıları, pnömotik ve hidrolik kontrol sistemleri ile yürüme fazlarına uygun bir hareket biçimi sağlar. Taşınabilir ve kişinin üzerine giyilebilir olması nedeniyle dış ortamlarda serbestçe hastaların dolaşımına izin verir. ${ }^{[26]}$ Giyilebilen robotik teknolojili cihazlara ileri ortezler de diyebiliriz. Bu cihazların daha küçük, taşınabilir ve daha hafif materyallerin kullanılarak yapılması ile gelecekte yaygın kullanımları klasik ortezlerin yerine geçmesini sağlar mı? Bugüne kadar yapılan çalışmaları inceleyerek bu soruya yanıt bulmaya çalışalım.

Serebral palside en sık rastlanan yürüme bozukluğu bükük diz yürüyüşüdür. Bükük diz yürüyüşünde diz, ilk temasta ve basma fazı boyunca aşırı fleksiyondadır. Salınım fazı sonunda dizdeki yetersiz ekstansiyon nedeni ile de adım uzunluğu kısalmıştır. Bu nedenle yürüme sırasında enerji harcanmasını artırmasının yanı sıra, diz ağrısı ve dizde dejenerasyona sebep olur. Gerek ortez kullanımı gerekse ortopedik cerrahi yaklaşımlar ile bükük diz yürüyüşü kontrol edilmeye çalışılsa da yürüme sırasında yeterli diz ekstansiyonunu sağlamak mümkün olmayabilir. Bu nedenle robotik yürüme cihazlarının kullanımı gündeme gelmiştir. Lerner ve ark. termoplastik KAFO'ya eklem hareketini kontrol eden robotik sensörlerin yerleştirilmesi ile bükük diz yürüyüşü yapan serebral palsili çocuklar için bir robotik ekzo-iskelet sistemi geliştirmişlerdir. Bu ortezde ayak bileği ve diz eklemlerinin açısal hızını kontrol eden motorlar, tork sensörleri ve kuvvete duyarlı resistörler mevcuttur. Cihazların ağırlığı 2,6-4 kg arasında değişmektedir. Aynı zamanda $2 \mathrm{~kg}$ ağırlığında pilli kontrol kutusu, kişilerin sırtında sırt çantası gibi taşınır (Şekil 4).[27] Bükük diz yürüyüşü yapan dört SP'li çocuğun üçünde $10^{\circ}$ 'den fazla ekstansiyon artışı görülmüştür. Bu çalışmada örneklem sayısı oldukça az olmakla birlikte SP'de ilk çalışmalardan biridir. Aynı araştırma ekibinin bükük diz yürüyüşü yapan SP'li çocuklarda yapmış olduğu bir başka çalışmada aynı robotik ekzo-iskelet sistemi bilgisayar oyun bazlı rehabilitasyon sistemi ile kullanılmış ve diz ekstansör aktivitesinde belirgin artış elde edilmiştir. ${ }^{[28]}$ Yine Lerner ve ark. bir başka çalışmada bükük diz yürüyüşü yapan çocuklarda ekzo-iskelet sisteminin güvenli, iyi tolere edilebilen bir sistem olduğunu ve bu sistemle çocukların bağımsız olarak yürüyebildiklerini göstermişlerdir. ${ }^{[29]}$ Aynı zamanda cihazın, sensörleri yardımıyla yürüme sırasındaki duruşu dinamik olarak düzelttiği görülmüştür. Bu nedenle bükük diz yürüyüşü yapan SP'li çocuklarda giyilebilen robotik ekzo-iskelet sistemlerinin yürümeyi iyileştirerek tedavi yöntemi olarak kullanılabileceği düşünülmüştür. Andrade ve ark.'nın yaptıkları bir başka çalışmada SP'li çocuklarda kullanılmak üzere lomber destekli HKAFO ile robotik sistemi kombine etmişlerdir (Şekil 5). Bu 


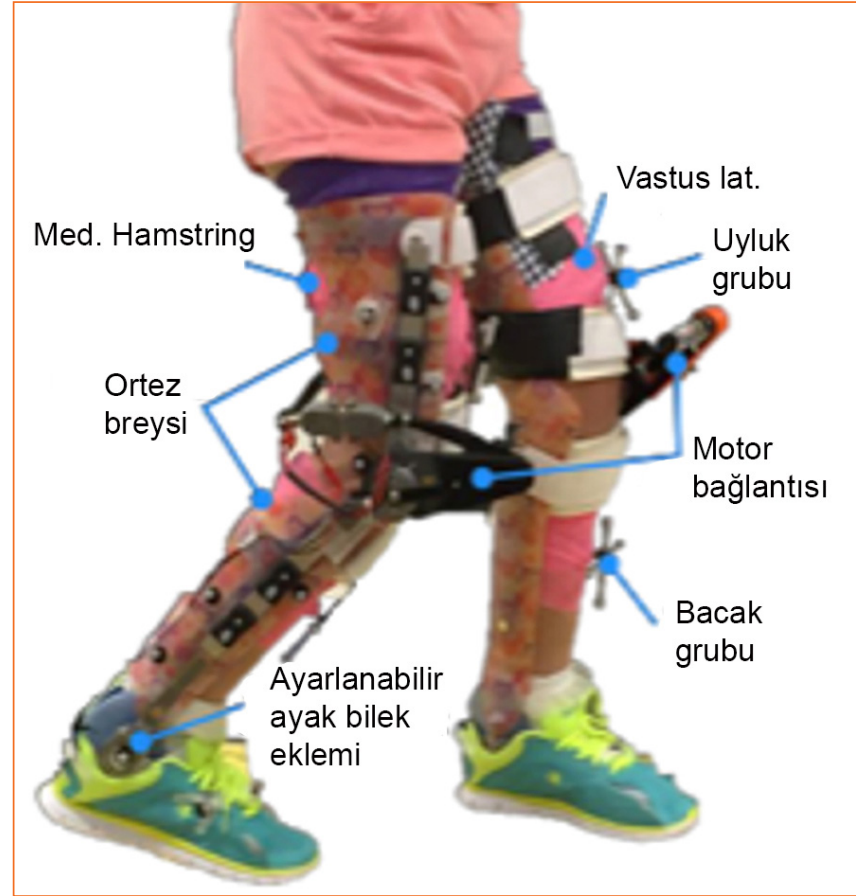

Şekil 4. Lerner ve ark.'nın geliştirdiği serebral palside bükük diz yürüyüşünde kullanılan ekzo-iskelet sistemi.[27] (Lerner'in izni ile kullanılmıştır.)

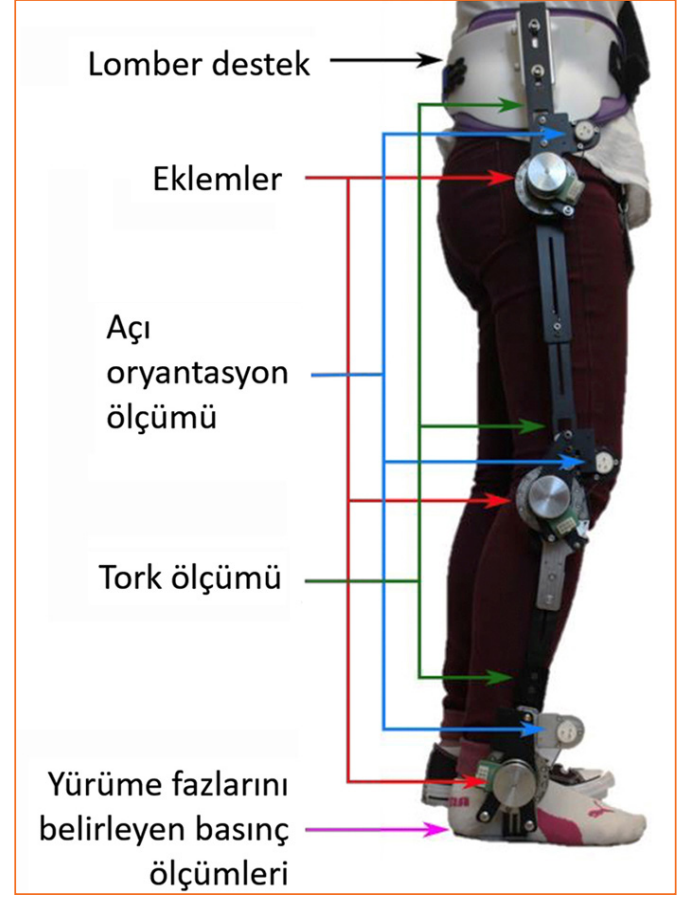

Şekil 5. Andrade ve ark.'nın geliştirdiği exoRoboWalker. ${ }^{[30]}$ (Andrade'nin izni ile kullanılmıştır.) cihazda ayak bileği, diz ve kalça eklemlerinde çalıştırıcılar mevcut olup, her bir eklem kendi elektrik üretici güce sahiptir. Tabandaki basınç algılayıcılar ile de yürüme döngüsünün fazlarına göre eklem hareket kontrolü sağlanarak yürüme biyomekaniği iyileştirilmeye çalışılır. ${ }^{[30]}$ Bir başka çalışmada daha hafif SP'li çocuklarda ayak bileği robotik motor kontrollü cihaz kullanımının yürüme üzerine etkileri değerlendirilmiştir. ${ }^{[31]}$ Bu cihazın kullanımı ile ayak bileği hareketlerinde açısal artış ve güç oluşturulmasının yanı sıra, \%19 oranında metabolik enerji harcanmasında azalma görülmüştür.

Patolojik yürüme paternlerinde yürüme sırasında enerji tüketiminin artmış olduğu iyi bilinmektedir. SP'li çocuklar yürüme sırasında normal yaşıtlarına göre $\% 80$ daha fazla enerji tüketmektedirler. Ekzo-iskelet kullanımı ile bu oran \%30'lara kadar düşmüştür. ${ }^{[32]}$ Klasik AFO kullanımı ile bu enerji tüketimini \%3 oranında azalmakta olup, ekzo-iskelet sistemleri ise \%14 oranında enerji tüketimini azaltmışlardır. ${ }^{[33]}$ Sabit robotik yürüme eğitimi yapan sistemler ile yapılan çalışmalarda SP'li çocuklarda motor performans ve endüransın arttığı görülmüştür. ${ }^{[34]}$

Giyilebilen, bağımsız hareketliliği sağlayabilen robotik-ortotik cihazlar halen geliştirilme aşamasındadır.
Kullanımın yaygınlaşabilmesi birçok faktöre bağlıdır. Bunların başında maliyet ve yaygın üretim gelmektedir. Serebral palside ortez reçetelerken temel hedefimiz deformiteyi kontrol edebilecek, yürümeye yardımcı en küçük fakat en etkin ortezin kullanılmasıdır. Bu nedenle sıklıkla AFO'lar kullanılır. Ekzo-iskelet robotik cihazlarda kontrolün sağlanabilmesi için cihazlar günümüzde klasik AFO'lardan daha uzun olup, KAFO veya HKAFO gibi daha yüksek seviyedeki cihazlardır. Ağırlıkları da klasik AFO'lardan fazladır. Bu nedenle yaygın kullanımlarını sağlayabilecek önemli bir diğer faktör ise daha küçük, hafif ve kullanım kolaylığı olabilecek cihazların geliştirilmesidir. Bu şekilde yürümenin gelecekte daha normalleşmesi belki de sağlanabilecektir.

\section{KAYNAKLAR}

1. Young J, Jackson S. Improved motor function in a preambulatory child with spastic bilateral cerebral palsy, using a custom rigid ankle-foot orthosis-footwear combination: A case report. Prosthet Orthot Int 2019:43(4):453-8. Crossref

2. Singerman R, Hoy DJ, Mansour JM. Design changes in anklefoot orthosis intented to alter stiffness also alter orthosis kinematics. J Prosthet Orthot 1999;11(3):48-56. Crossref

3. Eddison N, Mulholland M, Chockalingam N. Do research papers provide enough information on design and material used in ankle foot othoses for children with cerebral palsy? Systematic review. J Child Orthop 2017;11(4):263-71. Crossref 
4. White H, Jenkins J, Neace WP, Tylkowski C, Walker J. Clinically prescribed orthoses demonstrate an increase in velocity of gait in children with cerebral palsy: a retrospective study. Dev Med Child Neurol 2002;44(4):227-32. Crossref

5. Radtka SA, Skinner SR, Johanson ME. A comparison of gait with solid and hinged ankle-foot orthoses in children with spastic diplegic cerebral palsy. Gait Posture 2005;21(3):30310. Crossref

6. Wright E, DiBello SA. Principles of ankle-foot orthosis prescription in ambulatory bilateral cerebral palsy. Phys Med Rehabil Clin N Am 2020;31:69-89. Crossref

7. Van Gestel L, Molenaers G, Huenaerts C, Seyler J, Desloovere K. Effect of dynamic orthoses on gait: a retrospective control study in children with hemiplegia. Dev Med Child Neurol 2008;50(1):63-7. Crossref

8. Romkes J, Hell AK, Brunner R. Changes in muscle activity in children with hemiplegic cerebral palsy while walking with and without ankle-foot orthoses. Gait Posture 2006;24(4):46774. Crossref

9. Balaban B, Yașar E, Dal U, Yazıcıoğlu K, Mohur H, Kalyon TA. The effect of hinged ankle-foot orthosis on gait and energy expenditure in spastic hemiplegic cerebral palsy. Disabil Rehabil 2007;29(2):139-44. Crossref

10. Lucareli PRG, Lima MO, Lucarelli JGA, Lima FPS. Changes in joint kinematics in children with cerebral palsy while walking with and without a floor reaction ankle-foot orthosis. Clinics 2007;62(1):63-8. Crossref

11. Miller F. Durable medical equipment. In: Miller F, Cerebral Palsy. New York: Springer; 2005. p.181-249. Crossref

12. Wingstrand M, Hagglund G, Rodby-Bousquet E. Ankle-foot orthoses in children with cerebral palsy: a cross sectional population based study of 2200 children. BMC Musculoskelet Disord 2014;15:327. Crossref

13. Böhm H, Matthias H, Braatz F, Döderlein L. Effect of floor reaction ankle-foot orthosis on crouch gait in patients with cerebral palsy: What can be expected? Prosthet Orthot Int 2018;42(3):245-53. Crossref

14. Walker J, Stanger M. Orthotic management. In: Dormans JP, Pellegrino L, editors. Caring for Children with Cerebral Palsy: A Team Approach. Baltimore: Paul H Brookes Publishing; 1998. p.391-426.

15. Hylton NM. Postural and functional impact of dynamic AFOs and FOs in a pediatric population. J Prosthet Orthot 1990;2(1):40-53. Crossref

16. Buckon CE, Thomas SS, Jakobson-Huston S, Moor M, Sussman M, Aiona M. Comparison of three ankle-foot orthosis configurations for children with spastic diplegia. Dev Med Child Neurol 2004;46(9):590-8. Crossref

17. Buckon CE, Thomas SS, Jakobson-Huston S, Moor M, Sussman M, Aiona M. Comparison of three ankle-foot orthosis configurations for children with spastic hemiplegia. Dev Med Child Neurol 2001;43(6):371-8. Crossref

18. Wren TA, Dryden JW, Mueske NM, Dennis SW, Healy BS, Rethlefsen SA. Comparison of 2 Orthotic Approaches in Children With Cerebral Palsy. Pediatr Phys Ther 2015;27(3):218-26. Crossref

19. Radtka SA, Skinner SR, Dixon DM, Johanson ME. A comparison of gait with solid, dynamic and no ankle-foot orthoses in children with spastic cerebral palsy. Physical Ther 1997;77(4):395-409. Crossref
20. Romkes J, Brunner R. Comparison of a dynamic and a hinged ankle-foot orthosis by gait analysis in patients with hemiplegic cerebral palsy. Gait Posture 2002;15(1):18-24. Crossref

21. Ries AJ, Schwartz MH. Ground reaction and solid anklefoot orthoses are equivalent for the correction of crouch gait in children with cerebral palsy. Dev Med Child Neurol 2019;61(2):219-25. Crossref

22. Lintanf M, Bourseul JS, Houx L, Lempereur M, Brochard $S$, Pons C. Effect of ankle-foot orthoses on gait, balance and gross motor function in children with cerebral palsy: a systematic review and meta-analysis. Clin Rehabil 2018;32(9):1175-88. Crossref

23. Carvalho I, Pinto SM, das Virgens Chagas D, dos Santos JLP, de Sousa Oliveira T, Batista LA. Robotic gait training for individuals with cerebral palsy: a systematic review and metaanalysis. Arch Phys Med Rehabil 2017;98(11):2332-44. Crossref

24. Wu YN, Ren Y, Hwang M, Gaebler-Spira DJ, Zhang LQ. Efficacy of robotic rehabilitation of ankle impairments in children with cerebral palsy. Annu Int Conf IEEE Eng Med Biol Soc 2010;2010;4481-4. Crossref

25. Zhang M, Davies TC, Xie S. Effectiveness of robot-assisted therapy on ankle rehabilitation - a systemic review. J Neuroeng Rehabil 2013;10(1):30. Crossref

26. Reyes F, Niedzwecki C, Gaebler-Spira D. Technological advancement in cerebral palsy rehabilitation. Phys Med Rehabil Clin N Am 2019;31(1):117-29. Crossref

27. Lerner ZF, Damiano DL, Bulea TC. A Robotic Exoskeleton for Treatment of Crouch Gait in Children With Cerebral Palsy: Design and Initial Application. IEEE Trans Neural Syst Rehabil Eng 2017;25(6):650-9. Crossref

28. Bulea TC, Lerner ZF, Gravunder AJ, Damiano DL. Exergaming with a pediatric exoskeleton: Facilitating rehabilitation and research in children with cerebral palsy. IEEE Int Conf Rehabil Robot 2017;2017:1087-93. Crossref

29. Lerner ZF, Damiano DL, Bulea TC. A lower-extremity exoskeleton improves knee extension in children with crouch gait from cerebral palsy. Sci Transl Med 2017;9(404):eaam9145. Crossref

30. Andrade RM, Sapienza S, Bonato P. Development of a "transparent operation mode" for a lower-limb exoskeleton designed for children with cerebral palsy. IEEE Int Conf Rehabil Robot 2019:512-7. Crossref

31. Lerner ZF, Harvey TA, Lawson JL. A battery-powered ankle exoskeleton improves gait mechanics in a feasibility study of individuals with cerebral palsy. Ann Biomed Eng 2019;47(6):1345-56. Crossref

32. Weyland PG, Smith BR, Puyau MR, and Butte NF. The massspecific energy cost of human walking is set by stature. J Exp Biol 2010;213(23):3972-79. Crossref

33. Lerner ZF, Gasparri GM, Bair MO, Lawson JL, Luque J, Harvey TA, Lerner AT. An untethered ankle exoskeleton improves walking economy in pilot study of individuals with cerebral palsy. IEEE Trans Neural Syst Rehabil Eng 2018;26(10):198593. Crossref

34. Digiacomo F, Tamburin S, Tebaldi S, Pezzani M, Tagliafierro M, Casale R, Bartolo M. Improvement of motor performance in children with cerebral palsy treated with exoskeleton robotic training: A retrospective explorative analysis. Restorative Neurol Neurosci 2019;37(3):239-44. Crossref 